\title{
Palenques y Cimarronaje: procesos de resistencia al sistema colonial esclavista en el Caribe Sabanero (Siglos XVI, XVII y XVIII) $^{* *}$
}

\author{
Palenques and Marronage: resistance processes against \\ the colonial slaves system in the Sabanero Caribbean \\ (XVI, XVII and XVIII centuries)
}

\author{
Palanques e Cimarronagem: processos de resistência \\ escrava ao sistema colonial no Caribe Sabanero \\ (Séculos XVI, XVII e XVIII)
}

\footnotetext{
* Antropólogo y Sociólogo de la Universidad Icesi (Cali, Colombia). Maestrante de Desarrollo Territorial Rural en la Facultad Latinoamericana de Ciencias Sociales FLACSO (Ecuador). Investigador del Instituto de Estudios Interculturales de la Pontificia Universidad Javeriana (Cali).Correo electrónico: alencastano@yahoo.com, alencastano@gmail.com

** El presente artículo de reflexión es resultado de un proyecto de investigación adelantado por el Instituto de Estudios Interculturales de la Pontificia Universidad Javeriana de Cali, en convenio con el Instituto Colombiano de Desarrollo Rural (INCODER), en torno al estudio histórico de territorialidades ancestrales afrodescendientes y la necesidad de tierras de los consejos comunitarios a nivel nacional. Artículo recibido el 28/05/2015 y aceptado el 11/o8/2015.
} 



\section{Resumen}

Abstract

Resumo

Este artículo analiza las lógicas del cimarronaje y la constitución de los Palenques, como expresión de la resistencia de los esclavos negros contra el sistema colonial neogranadino. El análisis se centró temporalmente en los siglos XVI, XVII y XVIII, y espacialmente en la actual región del caribe Colombiano, específicamente las áreas conocidas como Bolívar Sabanero y la Depresión Momposina. A través de la conjunción de estas variables temporales y geográficas, el autor puede rastrear como los esclavos negros huían de sus amos usando dinámicas de cimarronaje, como una búsqueda de la autonomía social y territorial. Esta autonomía se materializa a través de la construcción de los Palenques en áreas específicas del Caribe colombiano, donde encontraron lo que el sistema colonial no le proporcionó a la población esclava de ese tiempo. En este sentido, este trabajo presenta algunas posiciones teóricas correspondientes al estudio de los afrodescendientes durante la época colonial en la región enfocada. El análisis puede contribuir a fortalecer la figura de entidades territoriales de Palenques y de un espacio geográfico que permitió a los cimarrones acceder a niveles de autonomía social a través de un uso particular y la apropiación de su territorio autóctono.

\section{PALABRAS CLAVE:}

Caribe Sabanero | palenques | cimarronaje | esclavitud | territorio

This article discusses the marronage logics (Cimarronaje) and the constitution of Palenque villages, as an expression of black slaves' resistance against the colonial neogranadian system. The analysis is temporarily focused on the 16th, 17th and 18th centuries, and spatially in the current Caribbean region of Colombia, specifically the areas known as Bolivar Sabanero and the Mompox Depression. Throughout the conjunction of these temporal and geographic variables, the author can track how black slaves ran away from their masters using marronage (cimarronaje) dynamics, as a pursuit for social and territorial autonomy. This autonomy was materialized through the construction of Palenque villages in specific areas of the Colombian Caribbean, where they found what the colonial system did not provide to the enslaved population of the time. In this sense, this paper presents some theoretical positions corresponding to the study of Afro-descendants during the colonial times in the 
focused region. The analysis could contribute to strengthening the figure of Palenque village's as territorial entities and a geographic space that allowed the Maroons to access levels of social autonomy through a particular use and appropriation of their native territory.

\section{KEYWORDS:}

Bolívar Savanna | palenque villages | marronage | slavery | territory.

Este artigo analisa as lógicas do Cimarronagem e a constituição dos Palanques, como expressão da resistência dos escravos negros contra o sistema colonial neogranadino. A análise se centralizou temporariamente nos séculos XVI, XVII e XVIII, e espacialmente na atual região do caribe colombiano, especificamente nas áreas conhecidas como Bolivar Sabanero e a Depressão Momposina. Através da conjunção destas variáveis temporárias e geográficas, o autor pode rastrear como os escravos negros fugiam de seus amos usando dinâmicas de cimarronagem, como uma busca da autonomia social e territorial. Esta autonomia se materializa através da construção dos Palanques em áreas específicas do Caribe colombiano, onde encontraram o que o sistema colonial não proporcionou à população escrava desse tempo. Neste sentido, este trabalho apresenta algumas posições teóricas correspondentes ao estudo dos afrodescendentes durante a época colonial na região enfocada. A análise pode contribuir com o fortalecimento da figura de entidades territoriais de Palanques e de um espaço geográfico que permitiu aos cimarrones o acesso a níveis de autonomia social através de um uso particular e da apropriação de seu território autóctone.

\section{PALAVRAS CHAVES:}

Caribe Sabanero | Palanques | Cimarronagem | Escravidão | Território 


\section{Introducción}

El presente artículo se construyó a partir de un proyecto de investigación, cuyo objetivo era el "Estudio de línea base a nivel nacional que caracterice las necesidades de tierra de las comunidades Afrodescendientes, Negras y Palenqueras en sus áreas de territorialidad ancestral". Como parte del mismo, se redactó un documento etnohistórico de las figuras de ancestralidad afrodescendiente a lo largo del territorio colombiano durante la época colonial. Se determinaron diversos lugares geográficos de análisis para este proyecto investigativo, siendo el Caribe Sabanero uno de ellos.

A partir de lo anterior, se indagó sobre las relaciones entre el contexto geográfico, actividades económicas realizadas por los esclavos, cimarronaje y palenques; así como la identificación de las zonas de influencia donde los pueblos cimarrones desarrollaban sus prácticas sociales, económicas y productivas durante la colonia. Para la recolección de información se realizó un proceso investigativo que recurrió a fuentes bibliográficas que permitieran construir un panorama general de la configuración tanto territorial como social de los asentamientos de negros esclavizados durante la colonia. Se escogieron determinados teóricos que durante las últimas décadas han incursionado en la historia de la esclavitud en el Caribe colombiano, decisión que permitió adquirir perspectivas diferentes a las desarrolladas por los académicos durante la segunda mitad del siglo XX.

Este barrido teórico permitió conocer las principales dinámicas de asentamiento y apropiación del territorio por parte de población negra esclavizada en el territorio del Caribe colombiano, resaltando las figuras de los palenques y el proceso de cimarronaje como expresiones de resistencia frente al sistema colonial instaurado durante los siglos XVI, XVII y XVIII. El presente artículo hace referencia a cada uno de estos procesos (construcción de palenques y lógicas de cimarronaje) como herramientas de supervivencia y confrontación al sistema económico y social colonial, cuyo eje era el uso de la mano de obra esclava.

La zona geográfica denominada Caribe Sabanero, está conformada por las zonas planas del río Magdalena que en la época colonial tuvieron fuerte presencia de comunidades negras esclavizadas, provenientes del puerto de Cartagena y que eran utilizados como fuerza de trabajo en grandes haciendas. El Mapa 1 ilustra el área de estudio, que gira en torno a dos zonas geográficas específicas del Caribe Sabanero: el área del Bolívar Sabanero, compuesto por las sabanas del actual departamento de Bolívar, y la Depresión Momposina, compuesta por las zonas más bajas del río Magdalena en el Caribe Colombiano.

En cada una de estas regiones se registrarán las principales apariciones de resistencia frente al sistema colonial neogranadino a partir de la constitución de fugas de cimarrones y constitución de palenques desde los siglos XVI hasta el XVIII. Una vez 
finalizada la presentación del proceso de cimarronaje y la constitución de palenques en el Bolívar Sabanero y en la Depresión Momposina, se culminará con una reflexión sobre estos procesos organizativos como una herramienta de resistencia frente al sistema colonial esclavista.

MAPA 1 Área de estudio: Caribe Sabanero Siglos XVI, XVII y XVIII

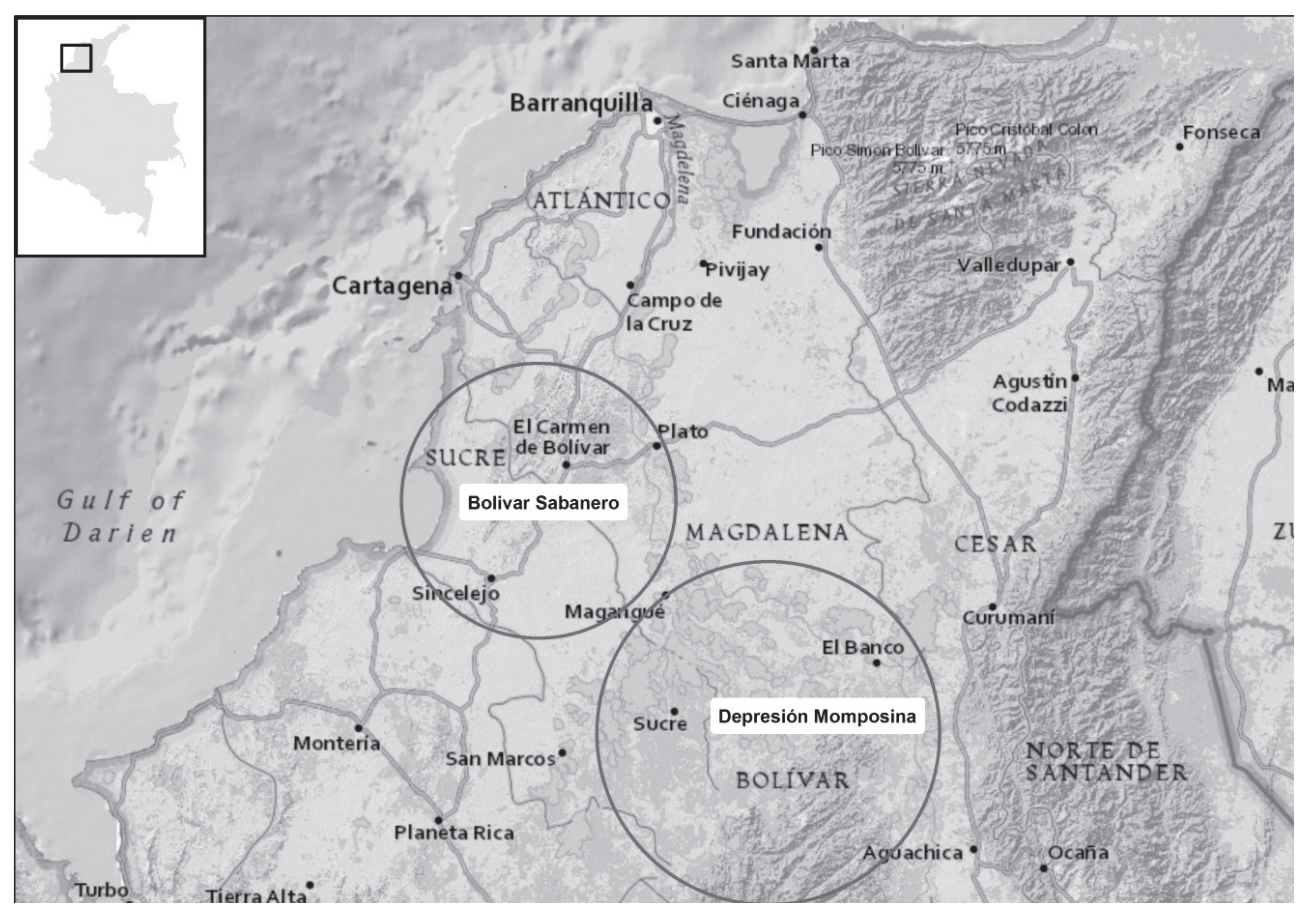

Fuente: construcción propia

\section{Palenques y cimarronaje: herramientas de resistencia al sistema colonial esclavista}

Los dos principales conceptos que guiaron el rumbo de investigación sobre la presencia de negros esclavizados y sus correspondientes asentamientos a lo largo del territorio de la Nueva Granada fueron: los palenques y el cimarronaje. Estos procesos iniciaron en el siglo XVI, pero es en el XVII cuando se evidencian las mayores expresiones de resistencia por parte de negros esclavos prófugos (cimarrones) frente al sistema colonial a través de la conformación de palenques (Navarrete, 2003).

El cimarronaje se refiere a los procesos de resistencia frente al sistema colonial neogranadino (Arrázola, 1986) en que los esclavos negros se fugaban de sus amos; "proceso por medio del cual los esclavos huían de la tutela de sus propietarios." 
(Navarrete, 2001: 88). El historiador inglés Anthony McFarlane (1991) establece dos tipos de razones por las que los esclavos huían: la primera alude a un escape temporal, colectivo o individual, con el objetivo particular de intentar regular, mejorar o cambiar el trato que recibían los esclavos por parte de sus amos; la segunda razón era escapar permanentemente de la esclavitud.

Esta dinámica de sublevación y fuga de los negros esclavizados, ya denominada y establecida como cimarronaje, conllevó a la consolidación y reconocimiento de una nueva forma de organización social en la colonia: los palenques. Explica McFarlane que aquellos cimarrones que querían romper con el sistema colonial que los apresaba, también aspiraban a la conformación de comunidades autónomas. Navarrete lo expone de la siguiente manera:

(...) cuando un número significativo de esclavos conseguía ponerse de acuerdo con sus intenciones de escapar después de superar las dificultades de la fuga, buscaba la forma de refugiarse en espacios de geografía difícil aunque con posibilidades de sobrevivencia, no muy distante de las estancias agrícolas, para construir palenques, reductos de libertad (Navarrete, 2003: 79).

McFarlane (1991), Navarrete (2001, 2003) y Arrázola (1986) exponen que el cimarronaje y palenques fueron mecanismos empleados por los negros esclavizados durante la colonia como expresiones de sublevación ante el sistema económico y social de la época. El cimarronaje fue una estrategia para mejorar sus condiciones de vida, ya fuera a través de la fuga permanente o como medio para que los amos mejoraran las condiciones de vida de los esclavos maltratados (McFarlane, 1991). Desde la perspectiva de Navarrete y Arrázola, los palenques tenían características diferentes, ya que condensaban aquellos cimarrones que tenían la convicción de vivir aislados del sistema colonial esclavista, y constituir espacios autónomos de vida social, económica y productiva en territorios alejados de la autoridad colonial. En un escenario donde las condiciones de vida de los negros esclavizados durante la colonia eran deplorables, la conformación de comunidades autónomas y asentamientos cimarrones los convirtió en (Navarrete, 2003).

El objetivo de esta presentación es visibilizar aquellas estrategias de resistencia realizadas por parte de una comunidad que carecía de las condiciones necesarias para una vida digna; y que a través de la implementación de lógicas de sublevación trataban de direccionar la búsqueda de espacios alternativos a los desarrollados por el sistema colonial. En este caso, ya fuese la instauración de una sociedad autónoma dentro de un territorio determinado, o la mejoría de sus respectivas condiciones de vida.

Estos procesos de resistencia identificados tanto en la zona del Bolívar Sabanero como en la Depresión Momposina durante los siglos XVI, XVII y XVIII, dependieron de la constitución de procesos históricos coloniales diferentes. Este ejercicio permitirá 
identificar los principales elementos que permitieron crear estos espacios de autonomía territorial, social y económica en el reino de la Nueva Granada.

\section{Constitución del cimarronaje y los palenques en el Bolívar Sabanero (Siglos XVI y XVII)}

Como fenómeno de resistencia de las poblaciones negras esclavizadas, el cimarronismo estuvo presente al norte del Nuevo Reino de Granada desde finales del siglo XVI, cuando los esclavos prófugos se iban convirtiendo en un gran problema para la sociedad de la costa caribeña. Diversos grupos de académicos que han reconstruido la historia colonial de las comunidades negras en Colombia, como María del Carmen Borrego Plá (1973 y 1994), han argumentado que los grupos de negros esclavizados al escapar de sus dueños construían palenques en zonas aledañas a los centros poblados con el objetivo de mantener algún tipo de contacto económico y social con estos.

En esta época el puerto de Cartagena era uno de los centros de mayor movimiento de esclavos en el continente, por ende, se convirtió rápidamente en uno de los polos de rebelión y huida de esclavos durante el periodo colonial. En 1570 esta ciudad condensaba aproximadamente unos ochocientos esclavos negros, más otros cuatrocientos que a lo largo de ese año fueron tomados de palenques cercanos. Este número se elevó a 1.776 esclavos entre 1589 y 1595 ; desde esta última fecha y hasta 1600 desembarcaron en este puerto 15.445 esclavos, número que ascendió a 35.311 entre 1604 y 1640 (Borrego Plá, 1994). A partir de esta dinámica de recepción de esclavos negros procedentes del África, la ciudad de Cartagena se fue convirtiendo en el principal puerto de comercialización de esclavos negros en el Nuevo Reino de Granada durante los siglos XVI y XVII.

A pesar que el término de cimarrón aparece en la Legislación de Indias en 1530, y su uso legislativo se desarrolla en las colonias a partir de 1540, en 1519 existían ordenanzas con el fin de evitar los levantamientos y huidas de esclavos negros en la época (Lucena, 2005). Borrego Plá (1973) argumenta que la ciudad de Cartagena contaba con las condiciones orográficas $^{1}$ que favorecían la huida de los esclavos; donde la existencia de alturas (aunque bajas) beneficiaban los asentamientos de cimarrones por el tupido terreno y difícil acceso al mismo. Por tal motivo, las sierras de Luruaco, y las de María eran las que presentaban el mayor porcentaje de población fugitiva en esta época. Del mismo modo, al sur de la provincia de Cartagena también se asentaba población esclava en la serranía de San Lucas.

En 1580, se tiene conocimiento de una expedición para destruir un palenque establecido en las cercanías de la barranca de Malambo, asimismo, en 1588 se conoce de otra expedición militar contra reductos de esclavos fugitivos en la zona de Santiago de Tolú. Del mismo modo, se identifica que en 1590, el Cabildo de Cartagena dicta una serie de ordenanzas 
contra los esclavos que habían escapado de sus dueños, enviando una comisión para la aprehensión de los asentados en los arcabucos² aledaños de la provincia (Borrego Plá, 1973).

Cada una de estas ordenanzas evidencia que en la segunda mitad del siglo XVI, específicamente a finales del mismo, se fue consolidando la problemática de la huida, resistencia y ataque de los esclavos negros hacia la población residente en los centros económicos y políticos de la época, así como la respuesta de la élite blanca hacia estos asentamientos. Toda esta dinámica hizo que se fueran consolidando refugios de cimarrones en las afueras de las villas como válvula de escape y resistencia a las lógicas de esclavitud.

La proliferación de procesos sublevación por parte de la población negra esclavizada no era fortuita. Como lo expresa Borrego Plá (1994), la presencia de población esclava ascendió de 800 en 1570 a 35.311 en 1640 al interior de la provincia de Cartagena; la autora argumenta que ese incremento sustancial se debió a la aprehensión de múltiples comunidades diferentes que residían a lo largo del continente africano; es decir, en la ciudad de Cartagena confluían un sinfín de pueblos y lenguas africanas en un solo sitio.

De este modo, resulta interesante concebir cómo los procesos de cimarronaje y de constitución de palenques pudieron traspasar las barreras lingüísticas de la población africana. Si estas comunidades eran traídas de diferentes lugares, ¿cómo se comunicaban entre ellos si tenían lenguas diferentes? En este caso, el objetivo común es la sublevación, la fuga y los levantamientos que se materializan a través de las lógicas del cimarronaje, sin importar las limitaciones lingüísticas de los pueblos. Así, se establecieron los mecanismos necesarios para crear una dinámica de comunicación cuyo objetivo principal era la fuga.

Tras la consolidación de los palenques y los reiterados ataques a la ciudad de Cartagena, esta dinámica permitió la multiplicación de los mismos a finales del siglo XVII, creando tres grandes regiones de influencia de los grupos cimarrones identificados por las autoridades de la provincia de Cartagena: compuestos por los palenques de Matudere y Betancur, situados en la Sierra de Luruaco, y compuestos exclusivamente por criollos. ${ }^{3}$ situados en la Sierra de María, donde los palenques más reconocidos y nombrados por la literatura y las autoridades de la época eran San Miguel y Domingo Angola (Arenal). eran principalmente dos palenques que estaban situados en la Serranía de San Lucas, entre los ríos Magdalena y Nechí (Borrego Plá, 1973). A continuación se expondrá la presencia de los palenques ubicados en estas tres grandes regiones en el Bolívar Sabanero.

2. Arcabuco: lugar de vegetación espesa casi selvática (Borrego Plá, 1973).

3. Por criollos se hace referencia a los negros esclavizados que nacieron y vivieron en el Nuevo Reino de Granada, y no provienen directamente del continente africano. 


\section{Ciénaga de Matuna y la provincia de Tolú (Inicios del siglo XVII)}

A finales de 1599 o comienzos de 1600 en el cabildo de Cartagena hubo un levantamiento dirigido por Domingo "Benkos" Biohó, que junto con su mujer, tres compañeros y otros esclavos de estancias ${ }^{4}$ cercanas (que en su totalidad sumaban treinta personas), salieron de las estribaciones de este cabildo para crear un asentamiento en el arcabuco de la Ciénaga de la Matuna, cerca de la villa de Tolú, a veinte leguas de la ciudad de Cartagena. En 1605, después de un fallido ataque al palenque de Matuna por parte del cabildo de Cartagena y Tolú, se reconoció formalmente la autoridad de Domingo Biohó en la zona (Navarrete, 2008). De este modo, Domingo "Benkos" Biohó se convirtió en el caudillo más reconocido de la época entre todos los esclavos negros de la región, liderando por muchos años la lucha y resistencia de los cimarrones contra el gobierno de Cartagena. Entre 1618 y 1619 muere Biohó tras una riña con unos guardias del presidio de la ciudad de Cartagena (Navarrete, 2008).

Una de las tesis principales de Navarrete (2008) era que el liderazgo del cimarronismo a principios del siglo XVII no era llevado a cabo por esclavos recién llegados del África que escapaban de sus propietarios; sino que se trataba de esclavos antiguos que conocían la región a causa de sus estadías en pequeños establecimientos de blancos que estaban a diez o veinte leguas de la ciudad de Cartagena.

Bajo esta premisa, se puede consolidar la idea que los negros esclavos con cierta antigüedad adquirieron vastos conocimientos sobre los arcabucos, sierras y montañas que rodeaban las estancias de los blancos; conocimiento que serviría como herramienta de resistencia y aislamiento frente a los colonos. Se evidencia así una lógica dialéctica entre el reconocimiento del territorio y la antigüedad de los esclavos al interior del mismo. Como lo expresa Navarrete, una de las claves para el desarrollo de asentamientos en la región del Caribe Sabanero durante el siglo XVI, fue la ubicación de palenques en áreas de difícil acceso por la espesa vegetación de las montañas y arcabucos. En este sentido, la apropiación del territorio por parte de las comunidades cimarronas se convirtió en una de las mejores armas de defensa de los palenques; configurándose dentro de la comunidad cimarrona, un saber específico en torno al territorio como mecanismo de protección y resistencia, donde el uso de las condiciones geográficas determinaba la supervivencia de las comunidades establecidas en palenques.

\section{Consolidación del cimarronaje en las estribaciones de la Sierra de María (Primera mitad del siglo XVII)}

El palenque de la Matuna, liderado por Domingo “Benkos" Biohó en 1599, fue el punto de partida para la constitución de otros palenques en la zona, como los establecidos en

4. Estancia: lugares donde existía algún tipo de actividad económica, donde los esclavos negros eran la principal fuerza de trabajo (Borrego Plá, 1973). 
la Sierra de María; los cuales ayudaron a gestar y a legitimar el palenque de San Miguel Arcángel, que se convertiría en 1713 en el poblado de San Basilio de Palenque. ${ }^{5}$

En 1622 se notifica en la villa de Tolú el alzamiento de un grupo de negros esclavizados, que se concentraron en la parte alta de la Sierra de María. En 1631, el gobernador de Cartagena daba cuenta de grupos de esclavos que se habían constituido en un palenque a veinte leguas de la ciudad, en las montañas y arcabucos del pueblo indio de Usiacurí. Las anteriores anotaciones permiten constatar la presencia de cimarrones en palenques en la Sierra de María, donde el terreno era montuoso y circundado por el río grande de la Magdalena (Navarrete, 2008).

En 1634 el gobierno de Cartagena notificó que desde hacía setenta años varios grupos de esclavos fugitivos habían formado poblados fortificados en la Sierra de María a doce leguas de la ciudad. Los principales palenques eran Piolín, Sanaguare y Limón, al que los otros daban obediencia. Estos palenques estaban retirados de los centros poblados, por lo que en sus inicios no promovían tantas rebeliones contra las villas y poblados (Navarrete, 2008).

Navarrete afirma la construcción de relaciones comerciales y económicas entre los palenques de la Sierra de María y las haciendas que la circundaban, con las que desarrollaban intercambios de herramientas y suministros por trabajo o pago por parte de los cimarrones (Navarrete, 2008). En este caso, el territorio no sólo se convertía en fortaleza y resguardo frente a las hostilidades de los blancos, sino que también se consolidaba como un organismo que permitía la interacción y el intercambio con otras comunidades asentadas junto al río Magdalena; como eran las estancias de blancos y otros palenques a lo largo del río.

Una de las motivaciones para la fuga y la conformación de palenques en esta época era la reconstrucción familiar: según el historiador McFarlane (1991), el esposo huía primero y luego regresaba por su esposa y sus hijos; a veces se conformaban grupos de parientes con la intención de huir a los palenques. Es decir, la figura del palenque estaba cargada de un fuerte simbolismo de resguardo y agrupación familiar para los esclavos que querían darse a la fuga; éste territorio brindaba la posibilidad de estar nuevamente con los familiares que habían sido esclavos por muchos años en las estancias de los blancos.

Las estancias de blancos que estaban en las estribaciones de Cartagena contenían gran número de esclavos negros. En 1687, en la provincia de esta ciudad había entre criollos y bozales ${ }^{6}$ más de 5.700 esclavos, distribuidos como se presenta, a continuación, en la tabla 1.

5. San Basilio de Palenque: primer pueblo libre de Suramérica.

6. La diferencia entre negros criollos y bozales es que los primeros eran esclavos nacidos o con mucho tiempo en el Nuevo Reino de Granada. Por negros bozales se hace referencia a los esclavos recién llegados del África. 
TABLA 1 | Población de negros esclavizados en Cartagena (1687)

Partido

No. de esclavos

\begin{tabular}{lc} 
Cartagena & 1.952 \\
\hline Tierra Adentro & 473 \\
\hline Barracas & 359 \\
\hline Majates & 197 \\
\hline Partido desde Turbaco, Arjona y Bahía & 558 \\
\hline Partido desde Metumilla y María, desde Matura hasta la jurisdicción de Tolú & 618 \\
\hline Villa de Tolú & 230 \\
\hline Río de Sinú & 230 \\
\hline Villa de San Benito & 311 \\
\hline Mompox & 628 \\
\hline Simití & 160 \\
Total & $\mathbf{5 . 7 1 6}$
\end{tabular}

De los 5.716 esclavos negros en toda la provincia de Cartagena, habían 3.764 fuera de la ciudad, de los cuales 3.364 (89\%) pertenecían a individuos particulares, 33 (o,8\%) a la Inquisición, 224 (5,9\%) a eclesiásticos y 143 (3,7\%) a funcionarios. Todos estos eran esclavos domésticos o del sector rural; tal condición permitía que fueran los que mejor iban conociendo el territorio, los que sabían los caminos de huida hacia los terrenos montuosos que lo circundaban.

\section{La Otra Banda. Palenques en el Río Magdalena (Segunda mitad del Siglo XVII)}

En 1655 se hizo evidente un conflicto de intereses entre los gobernadores de las provincias de Cartagena y Santa Marta por la jurisdicción de un palenque equidistante a las dos ciudades. El problema giraba en torno a las acciones violentas que impulsaba el gobernador de Cartagena contra un palenque constituido al otro margen del río Magdalena, formado por fugitivos cimarrones de la banda izquierda del mismo río. Este palenque estaba en las cercanías de Barranca, a cinco leguas del Caño San Antonio. Por su parte, el gobernador de Santa Marta defendía sus derechos de jurisdicción sobre este lugar.

Navarrete afirma que los fundadores de este palenque fueron negros que huyeron de la destrucción del palenque Limón, aproximadamente en 1634. El paso de fugitivos de la gobernación de Cartagena que constituían palenques en la banda izquierda 
del río Magdalena, se debió a que los cimarrones de esta gobernación buscaban ampararse en las políticas de no agresión contra los palenques del gobierno de Santa Marta (Navarrete, 2008).

Los palenques de la otra banda (derecha) del río Magdalena fueron parte de la fuerte presencia de asentamientos cimarrones durante el siglo XVII, tanto en las márgenes del río Magdalena como en las sabanas que lo circundan. La confrontación de las comunidades cimarronas y el sistema colonial por la apropiación del territorio tuvo su auge a lo largo de este siglo. Los principales y más representativos palenques en esta zona fueron Tapia, Guaimaral, Gambanga y La Magdalena, los cuales se convirtieron en espacios de refugio y traspaso por parte de población cimarrona de otros palenques aledaños a esta zona, que debido a ataques de las autoridades coloniales de la época, tenían que consolidar espacios de resistencia en diferentes partes del territorio del Bolívar Sabanero (Navarrete, 2008).

\section{Palenque de San Miguel Arcángel y la Otra Banda: puntapié para la constitución de San Basilio de Palenque en los Montes de María (Finales del Siglo XVII y comienzos del XVIII)}

La constitución del palenque de San Miguel Arcángel se relaciona con la existencia de varios palenques en la Sierra de María, así como algunos constituidos en la banda derecha del río Magdalena (la Otra Banda). Los dos palenques de la Otra Banda eran los de Gambanga y La Magdalena, éste último ubicado a orillas del río, a seis leguas de su desembocadura y dentro de la jurisdicción de Santa Marta.

A mediados del siglo XVII ya existía el palenque de Domingo Angola (Arenal) y el de Joyanca; posteriormente se constituyeron los de San Miguel y Duanga ${ }^{7}$ al lado izquierdo del río Magdalena. En este mismo lugar también existió el palenque de Manuel Embuyla, cuando a finales del siglo XVII los cimarrones de la Sierra de María fueron atacados por la gobernación de Cartagena, haciendo que los pobladores se reagruparan en otros palenques como los de Arroyo Piñuela y Zaragocilla (Navarrete, 2008).

La presencia de tales asentamientos a lo largo del río Magdalena y en sus inmediaciones, permite arriesgarse a afirmar que no sólo había comunicación entre los palenques ubicados al interior de la Sierra de María, sino que los mismos cimarrones circulaban de un palenque a otro, ya fuera por voluntad propia o por amenazas. Ante estas situaciones la gente se trasladaba a otros palenques o en ciertas ocasiones estos se fusionaban entre sí.

La fundación del palenque de San Miguel Arcángel data entre 1655, cuando varios grupos cimarrones se pasaron de la banda derecha (gobernación de Santa Marta) a la izquierda

7. Hay que tener en cuenta los palenques anteriores, como el del pueblo de Usiacurí, a veinte leguas de Cartagena, y los de Limón, Piolín y Sanaguare, a doce leguas de la ciudad. 
(gobernación de Cartagena), y 1674, cuando fueron atacados y destruidos los palenques de San Miguel, Joyanca y Domingo Angola (Arenal). Después de la reconstrucción de los palenques, Domingo Criollo fundó el de San Miguel Arcángel, que luego se convertiría en el palenque más extenso e importante de toda la Sierra de María.

A medida que se consolidaron los palenques en esta localidad, desarrollaron una economía específica y detallada. En términos generales, se mantenían de la caza, la pesca y la agricultura. El reconocimiento del territorio y su explotación fueron claves de la constitución de una economía recolectora y agrícola de subsistencia. Como se describió antes, los cimarrones establecieron relaciones económicas con las estancias de blancos alrededor de la Sierra de María; desarrollaron dinámicas de intercambio durante casi un siglo, formando una red económica dentro del sistema colonial.

Después de numerosos enfrentamientos entre la gobernación de Cartagena y los palenques de la Sierra de María, en 1694 fue conquistado y destruido el palenque de San Miguel de Arcángel. Los sobrevivientes de estos palenques quedaron esparcidos hasta que finalizando la década de 1690, grupos cimarrones repoblaron el palenque de San Miguel de Arcángel junto a los nuevos cimarrones escapados de las estancias cercanas a la Sierra de María.

A principios del siglo XVIII este palenque condensaba un número importante de cimarrones, y el capitán general de Cartagena estaba en una encrucijada: atacar militarmente el palenque y recomenzar un sinfín de enfrentamientos, o lograr la pacificación de los cimarrones por medio de un indulto. El 21 de noviembre de 1713, el gobernador de Cartagena ordena al capitán Alfonso de Guzmán escribir al palenque de San Miguel de Arcángel para que establecieran un acuerdo de paz entre las dos partes, bajo amenaza de ataque. El 9 de diciembre del mismo año, un grupo de cimarrones visitó en Cartagena al obispo de la ciudad, don Antonio María Cassiani, para desarrollar un acuerdo de paz. El gobernador de Cartagena decidió subdelegar su jurisdicción en el obispo para que este pudiera negociar con el palenque de San Miguel de Arcángel (Ruiz, 2001).

El 22 de diciembre de 1713 se expidió un documento donde se concedía el indulto y se permitía el comercio con los españoles a todos los cimarrones que habitaban en el palenque de San Miguel de Arcángel. El 17 de enero de 1714, el obispo Antonio María Cassiani llegó al palenque de San Miguel de Arcángel donde, con el caudillo criollo Nicolás de Santa Rosa, discutieron y aprobaron un acuerdo de paz. Este mismo día erigieron la iglesia del pueblo, nombrando a don Isidro de Osorio, sacerdote de la orden de San Basilio, como párroco de la población a la que denominaron San Basilio Magno. Con este acuerdo de paz, se legitimó la existencia del palenque de San Miguel Arcángel (ahora llamado San Basilio Magno), considerado parte del sistema colonial y sujeto a la legislación española (Ruiz, 2001).

En 1777, se realizó en San Basilio de Palenque un censo poblacional, el cual arrojó los siguientes datos: 


\begin{tabular}{|c|c|c|}
\hline TABLA 2 & \multicolumn{2}{|c|}{ Censo poblacional en San Basilio de Palenque: Sexo y Edad (1777) } \\
\hline Rango Edad & Hombres & Mujeres \\
\hline 5 & 41 & 64 \\
\hline 10 & 62 & 51 \\
\hline 15 & 38 & 41 \\
\hline 20 & 40 & 42 \\
\hline 25 & 25 & 21 \\
\hline 30 & 15 & 27 \\
\hline 35 & 28 & 16 \\
\hline 40 & 10 & 14 \\
\hline 45 & 17 & 15 \\
\hline 50 & 7 & 2 \\
\hline 60 & 4 & 8 \\
\hline 70 & 13 & 9 \\
\hline 80 & 2 & $\mathrm{O}$ \\
\hline 90 & 4 & $\mathrm{O}$ \\
\hline Total & 306 & 310 \\
\hline
\end{tabular}

Fuente: Archivo Histórico Nacional Censos Varios. T.8 f.833r - 839v (Blanco, 1995)

En la tabla 2 se puede observar la distribución poblacional que tenía San Basilio de Palenque en 1777 un total de 616 residentes, de los cuales el 49,2\% eran varones y el 50,8\% restante mujeres. Del mismo modo, se puede establecer que dentro de la anterior tabla poblacional de este censo, el $45 \%$ de la población (hombre y mujer) están en el rango de edad entre 15 y 45 años, representando una comunidad joven y con una fuerza de trabajo activa.

Esto es de suma importancia en la historia de la resistencia cimarrona y palenquera en la región del Bolívar Sabanero. Como se expresó en los anteriores acápites, toda la región de las sabanas de la provincia de Cartagena y los valles ubicados en las inmediaciones del río Magdalena fue un territorio de resistencia para las comunidades negras fugadas de la esclavitud, para quienes los palenques fueron espacios de autonomía territorial, social y económica.

Durante más de dos siglos, la relación entre las comunidades palenqueras y las autoridades coloniales se caracterizó por la tensión y la guerra; pero cuando San Miguel de Arcángel fue reconocido y se conviertió en espacio libre de cualquier hostigamiento por parte del sistema colonial, marcó un hito en más de doscientos años de historia de los palenques como mecanismos de resistencia y autonomía territorial. 
MAPA 2 $\quad$ Principales Palenques del Caribe Sabanero. Siglo XVII

\section{Principales Palenques del Caribe S. XVII}

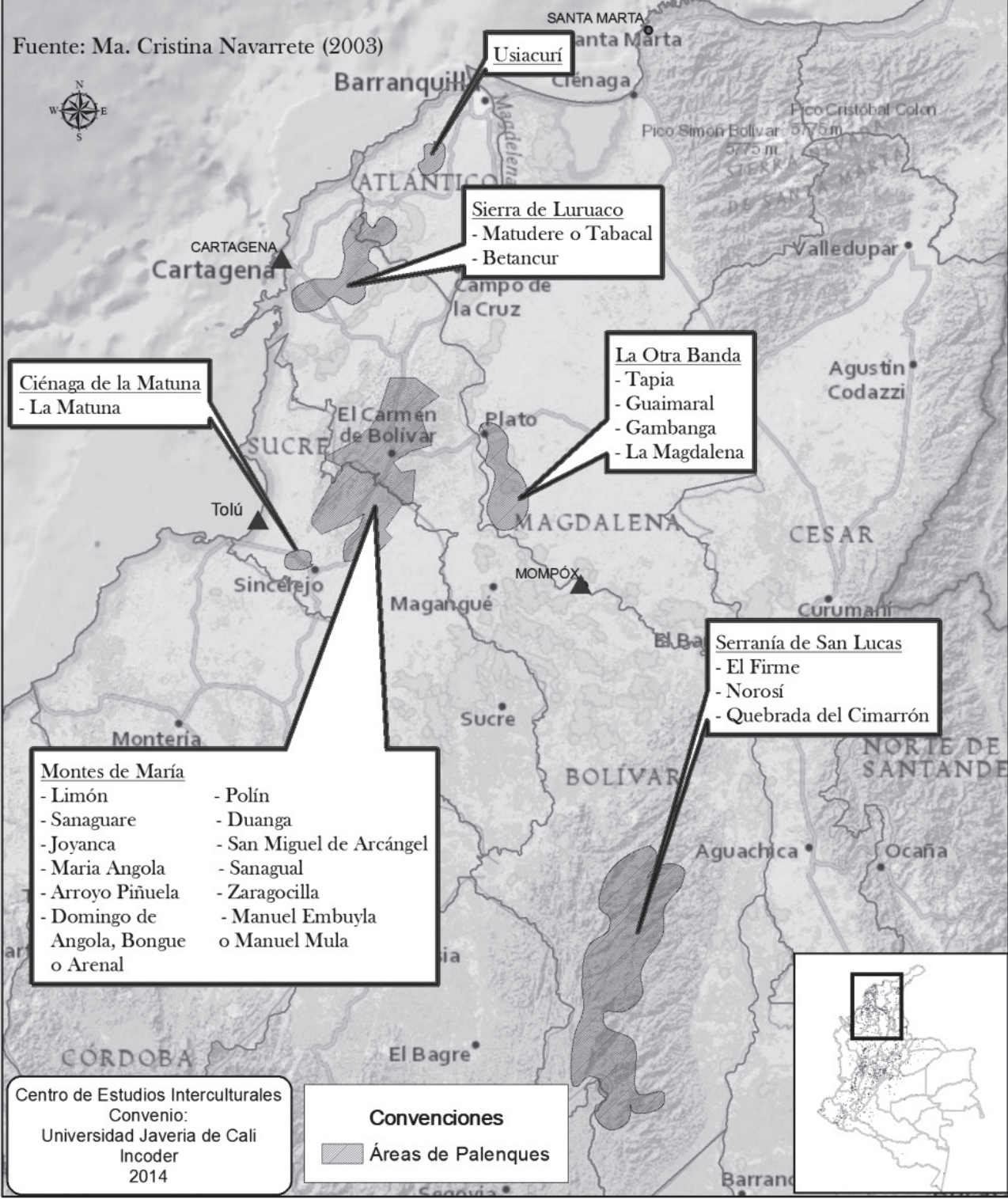


A manera de síntesis, se cierra esta primera parte del artículo con una representación cartográfica de las áreas de influencia de los palenques en el Caribe Sabanero a lo largo del siglo XVII. La segunda parte del escrito ahondará sobre las lógicas del cimarronaje y la constitución de palenques en las zonas más bajas del río Magdalena, en la región de la actual Depresión Momposina.

\section{Mompóx y Loba. La relación con el “otro” en la época colonial en la Depresión Momposina (Siglo XVI)}

Durante la época colonial, el río Magdalena fue eje de la configuración territorial, comercial y social al interior de la antigua gobernación de Cartagena; a través del río la ciudad principal de la provincia desarrolló numerosas actividades comerciales, el tráfico económico y comercial se centraba en la villa de Mompox, puerto de adecuada infraestructura para el transporte mercantil y abastecimiento de víveres para toda la región.

Las particularidades territoriales de la villa de Mompox, zonas bajas del río Magdalena, tierra pantanosa y llena de manglares, permitieron ejercer una lógica comercial y fluvial sin grandes actividades agropecuarias. Se organizó una especie de transporte fluvial denominado en que los indígenas trabajaban de manera obligada y sin remuneración como remeros en canoas que surcaran el río Magdalena, llevando y trayendo mercancías entre la ciudad de Cartagena y el centro de la Nueva Granada (Borrego Plá, 1983).

Esta situación hizo que la villa de Mompox fuera monopolizando el transporte fluvial en la gobernación de Cartagena, convirtiéndose en el segundo puerto más importante de esta gobernación colonial. Ya en 1560, este puerto era el lugar de residencia de los encomenderos principales de la zona (Ybot, 1952). A lo largo del siglo XVI, la boga se fue consolidando como el eje central de la economía en esta villa, hasta el punto que en 1598 el visitador del Río Grande de la Magdalena, Martín Camacho, conseguiría reemplazar a los indígenas de la zona por negros esclavizados traídos de Cartagena; durante los siglos siguientes la mano de obra esclava negra se utilizó en esta actividad (Borrego Plá, 1983).

Ya desde el 3 de mayo de 1537 (fecha de su fundación realizada por Alfonso de Heredia), la Villa de Mompox se convirtió en uno de los principales centros fluviales de la colonia, junto con Tamalameque (Sompallón), ubicada al sur, y con Tenefire, fundada al norte. Durante todo el siglo XVI, los colonizadores impusieron la esclavitud del indio, la mita $^{8}$ y el trabajo forzoso en la boga del río. La esclavitud en la Depresión Momposina, como en todas las regiones de la época colonial, era producir renta mediante el trabajo del esclavo. Ejemplo de ello fue la fundación de las tierras de Loba, cuando Diego Ortíz Nieto tomó posesión de cincuenta esclavos y se radicó en estas tierras. A partir

8. Sistema de trabajo forzado impuesto por el Estado Imperial a los indígenas y negros esclavizados para su propio beneficio. 
de este periodo se evidencian diversas luchas entre cimarrones y amos españoles como consecuencia de toda esa relación de tensión entre los esclavos africanos y sus propietarios blancos en la provincia de Cartagena, lideradas por Domingo "Benkos" Biohó y los palenques de La Matuna y Norosí, entre 1599 y 1637.

El palenque de la Matuna llegó hasta las inmediaciones de la villa de Mompox y la zona de Loba, la proclamación de "Benkos" Biohó como el "rey del arcabuco" y el reconocimiento del mismo como autoridad, les permitió a los esclavos prófugos de la Depresión Momposina copiar sus formas de organización social a lo largo de esta región. Los esclavos fugitivos se habían organizado a lo largo de la zona de Loba y la Depresión Momposina en palenques agrícolas y mineros (Fals Borda, 1976).

Las estrechas relaciones entre la ciudad de Cartagena y la villa de Mompox no solo permitieron tejer lazos comerciales y económicos entre las élites sociales de la época, sino también conocer las lógicas de resistencia que se establecían alrededor del puerto negrero de Cartagena. Las noticias en torno a Benkos Biohó impulsaron otras acciones de sublevación e intentos de constitución de espacios de autonomía territorial alrededor de la villa de Mompox a través de la instauración de palenques.

Se debe resaltar que, a pesar de que las condiciones geográficas no son similares entre estas dos regiones (las sabanas y las zonas inundables del río Magdalena), las comunidades negras esclavizadas hicieron uso de la misma forma para su beneficio. Como se expresaba con anterioridad, la región de la villa de Mompox era muy pantanosa y proliferaban los manglares, elementos de la naturaleza que también fueron utilizados por los cimarrones como medios de protección y resistencia. En este caso, también hubo un aprovechamiento de la geografía, la apropiación y uso del territorio como medio de protección para los palenques y la población que residía al interior de la misma. La presencia de palenques en esta región se desarrolló a partir del siglo XVII, a través de la guerra de Norosí.

\section{Repercusiones de la guerra del Norosí en la configuración social-esclavista de la Depresión Momposina (Siglo XVII)}

Así como en la ciudad de Cartagena, en Mompox se presentaron innúmeros escapes de negros esclavizados durante el siglo XVII, los cuales se dirigían hacia el sur y occidente de esta villa a través de caños y playones en áreas montuosas y de difícil acceso. En este caso, la región de Tiquisio y Norosí, en los brazos del río Magdalena denominados Rosario y Loba, así como en las ciénagas de Simití, eran las zonas de influencia los palenques (Fals Borda, 1979).

Para contrarrestar esta problemática social entre los esclavos fugitivos y sus propietarios, las autoridades de la villa de Mompox y Tamalameque en 1617 hicieron un primer ataque contra los palenques de la zona de Tiquisio y Norosí. Después de unas 
cuantas intervenciones, las autoridades de estas villas en 1637 los destierran y se quedan con las tierras fértiles y ricas en oro del cerro de Norosí (Fals Borda, 1979).

En 1691 ya se habían identificado nuevos palenques en el río San Jorge y las orillas del río Magdalena, así como en la serranía de San Lucas y San Juan. Entre 1692 y 1693 una expedición de la gobernación de Cartagena contra los cimarrones y palenques de la Sierra de María se extendió hasta el sur de la provincia, en lugares de influencia de Mompox y las Tierras de Loba, en la parte de Norosí. Después de los ataques contra los palenques identificados en esta zona, los sobrevivientes construyeron palenques en la región de San Jorge (Lorenzana, Uré, Carate y Cintura) y sobre el río Cauca (palenque El Guamal, muy cerca de Norosí). Por otra parte, se fueron consolidando pueblos negros que no llegaron a ser palenques, como Tiquisio, Papayal, Morales, Masanga, Corrales y Ladera de Judas (Fals Borda, 1979).

Tales enfrentamientos entre la autoridad colonial y los asentamientos palenqueros, denotan la región de Norosí como una de las zonas con mayor presencia de población cimarrona en la región. Como se expresó antes, durante el siglo XVII se evidenció la mayor presencia de palenques y pueblos cimarrones en la Depresión Momposina, no solo habitaban las partes bajas del río Magdalena, también se adentraron en la región del Bolívar Sabanero, en la espesa vegetación de las serranías cercanas como las de San Lucas y San Juan.

Es reducida la bibliografía que hace referencia a las lógicas de resistencia y autonomía al interior de los palenques ubicados en la región de la Depresión Momposina durante el siglo XVII, pero entre lo poco que hay resalta la ubicación de los mismos. Como ya se expuso, las condiciones geográficas en el Bolívar Sabanero y la Depresión Momposina eran diferentes, lo cual fue determinando el uso de la mano de obra esclava en la región; en el Bolívar Sabanero la fuerza esclava era utilizada en la agricultura, mientras que en la Depresión Momposina se enfocó principalmente en el transporte fluvial.

Se observa que a medida que conocía su medio geográfico, la población negra esclavizada lo usaba en su propio beneficio para la constitución de palenques en áreas de difícil acceso, como estrategia de refugio frente a los hostigamientos de las autoridades coloniales de la época. Esta relación entre territorio y conocimiento fue una de las dinámicas constitutivas del quehacer del cimarronaje al interior de esta región.

\section{Continuidades poblacionales de grupos cimarrones en las estribaciones de la Depresión Momposina (Siglo XVIII)}

Para esta época, la serranía de San Lucas todavía comprendía los asentamientos palenqueros de Norosí, y el Arenal; así como el centro poblado de San Bartolomé de Buenavista. La principal característica poblacional de estos asentamientos era la 
presencia de negros cimarrones, esclavos y unos cuantos blancos. En esta área selvática y montañosa se fue consolidando una zona de movilidad, refugio y resistencia de los negros esclavizados, a través de la constitución de palenques, frente a las estancias y minas ubicadas al norte de la provincia de Antioquia (Remedios, Cáceres, Zaragoza y Guamocó), como aquellos ubicados en la jurisdicción de la villa de Mompox (Loba, Norosí y Tiquisio) (Arcila y Gómez, 2003).

A finales del siglo XVIII, la villa de Mompox consolidaba un número poblacional considerable, aproximadamente 7.118 personas (Tovar, 1994). En esta ciudad había dos modalidades legales para poder obtener la libertad: por voluntad del amo o a través de la transacción negociada. Por tal motivo, era recurrente el ahorro de dinero entre la comunidad de negros esclavizados como estrategia para comprar su libertad, gracias a las leyes como las Siete Partidas, la cual permitía a los esclavos ahorrar dinero para este fin (Munive, 2006).

Fueron pocos los negros esclavizados que pudieron acceder a la libertad, a pesar de esta ley, pues no había condiciones suficientes dentro del sistema colonial que permitieran la preservación de esta condición de libertad en las comunidades esclavizadas. Por tal motivo los esclavos optaban por huir, como venían haciendo desde siglos atrás.

Del mismo modo, en esta región se observa una dinámica de relación diferencial entre los palenques. Se identificó intercambio de movilidad y resistencia entre los asentamientos cimarrones de la Depresión Momposina con los de la antigua gobernación de Antioquia. Lo interesante es que, a pesar de una geografía diferente, así como diferente uso de la mano de obra (en la Depresión Momposina principalmente para el transporte fluvial y agricultura, en la gobernación de Antioquia únicamente para las minas) propiciaron lugares de refugio que paulatinamente se convirtieron en zonas de encuentro entre grupos cimarrones que se fugaban de sus amos. Es decir, siempre hubo un fuerte y constante contacto a lo largo de este siglo entre los palenques ubicados al norte de la gobernación de Antioquia y los de las sabanas de la gobernación de Cartagena.

Para finalizar este acápite dedicado a la Depresión Momposina, se hace una caracterización cartográfica de cada uno de los palenques y pueblos cimarrones de la región entre los siglos XVI y XVIII. 
\begin{tabular}{l|l} 
MAPA 3 & Palenques y pueblos cimarrones \\
& en la Depresión Momposina.
\end{tabular} Siglos XVI, XVII XVIII

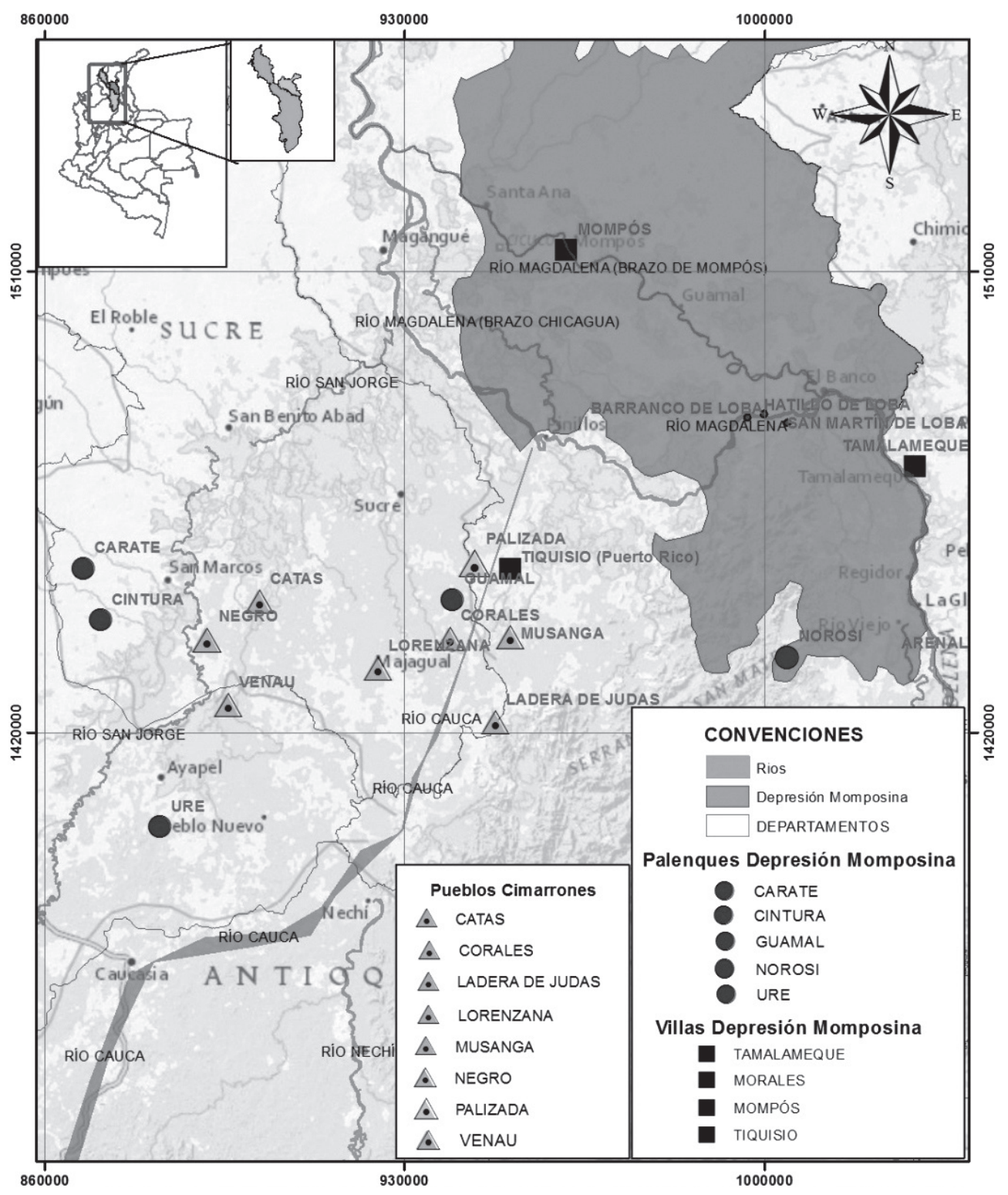

Fuente: Fals Borda, Orlando, 1979, 1976

9. Se aclara la diferencia entre palenques y pueblos cimarrones. Los primeros comprenden aquellos grupos cimarrones con una estructura social, económica y política consolidada. Pueblos cimarrones son grupos que han escapado de sus respectivos propietarios, pero que no alcanzaron a desarrollar una fuerte estructura organizativa sociopolítica y económica en su interior. 


\section{Algunas consideraciones en torno a la territorialidad palenquera de los Siglos XVI, XVII y XVIII en el Caribe Sabanero}

A lo largo de este texto se tomaron como referencia geográfica dos lugares particulares del territorio de la antigua gobernación de Cartagena, en los que durante tres siglos (XVI, XVII y XVIII) se desarrolló un fuerte proceso de cimarronaje y constitución de palenques: el Bolívar Sabanero y la Depresión Momposina. En cada una de estas regiones se observó una fuerte presencia de población negra esclavizada a comienzos de la primera mitad del siglo XVI, la cual se consolidó a inicios del XVII. A partir de esta sobrepoblación de esclavos, el historiador Adolfo Meisel Roca expone:

\footnotetext{
No es extraño, por tanto, que el cimarronaje hubiera sido un fenómeno generalizado. En la antigua provincia de Cartagena el cimarronaje fue un fenómeno permanente pero alcanzó su mayor intensidad a fines del siglo XVII. Se explica que ello hubiera ocurrido en ese periodo, ya que el cimarronaje está en relación directa con el volumen de importaciones, pues los bozales (esclavos recién importados), al no estar acostumbrados al esclavismo son más susceptibles a la fuga (Meisel, 1980: 246).
}

Este argumento permite concebir el proceso de cimarronaje como un fenómeno generalizado en aquellos centros poblados donde las importaciones de esclavos se realizaban de manera constante; en este caso, los puertos de importancia económica como Cartagena y la villa de Mompox. Del mismo modo, expresa que esta población, al no estar acostumbrada al esclavismo, era más susceptible a la fuga. Esta argumentación no debe ser vista simplemente como un proceso de escape, sino como un medio para un fin específico, como mecanismo de confrontación del sistema colonial.

Desde esta perspectiva se deben retomar las postulaciones realizadas por Anthony McFarlane, quien caracterizó dos tipos de fuga por parte de los negros esclavizados: las de carácter temporal y las definitivas. Frente a las primeras, este historiador pregona que aquellos esclavos que realizaban fugas temporales no siempre tenían el objetivo de lograr su libertad, sino que deseaban conservar algunas prerrogativas; por ejemplo, mejores condiciones laborales, sociales y de salubridad en sus lugares de trabajo. Es decir, huían con el objetivo de regular o mejorar el trato que recibían dentro de la esclavitud. Por otra parte, las fugas definitivas eran de esclavos que, en grupo o individualmente, buscaban alcanzar la libertad total (McFarlane, 1991).

Las apreciación de McFarlane permite concebir que tales acciones de fuga se convertirían en una forma de resistencia contra el sistema esclavista colonial, no solo por la aspiración a una ruptura total del cautiverio, consolidando comunidades de vida autónoma a través de palenques; las lógicas de sublevación y huída también 
se convertían en mecanismos mediante las cuales pedían a sus amos prerrogativas específicas en torno a una mejor calidad de vida.

En este sentido, también hay que precisar que la constitución de los palenques a lo largo del Bolívar Sabanero y la Depresión Momposina dependió del conocimiento del territorio que tenían los grupos cimarrones que decidían emprender la huida de sus propietarios. Los beneficios de este conocimiento eran la posibilidad de ubicar los mejores lugares para construir los palenques. La variable que primaba era conseguir espacios de vegetación tupida y de difícil acceso. En este caso, los arcabucos y las ciénagas eran herramientas de resistencia de los palenques frente a los ataques de los blancos.

Es decir, las diversas lógicas que giraban alrededor del uso y apropiación del territorio configuraron las dinámicas de supervivencia de las comunidades cimarronas que decidían constituir espacios de autonomía territorial, social y económica a través de los palenques. De este modo, la consolidación de palenques en espacios de difícil acceso les propiciaba un mejor modo de resistencia frente a cualquier tipo de avanzada colonizadora, convirtiéndose en una defensa natural de los palenques dentro de la gobernación de Cartagena.

La autonomía que se ejercía en estos espacios geográficos superaba las barreras de lo meramente territorial. El proceso de constitución de palenques por largos periodos, permitía ir constituyendo una relación de dependencia con el territorio, no solo al desarrollar prácticas agrícolas del pancoger, sino también al realizar prácticas de intercambio social y económico con los centros poblados que existían dentro de las áreas geográficas del Bolívar Sabanero y la Depresión Momposina. Así, el territorio propiciaba a los palenqueros la oportunidad de entablar relaciones con los poblados aledaños, y no estar completamente aislados del entorno social. Tales relaciones permitieron tejer redes de intercambio comercial y productivo, generando una interacción con el "otro blanco", y logrando consolidarse como una estructura autónoma en la región (Borrego Plá, 1973).

Estas nuevas formas de territorialidad y apropiación del espacio desarrollado por los palenques pretendían establecer un tipo de sociedad diferente al sistema colonial esclavista, el cual estaba conformado en función a las necesidades de su propia reproducción. Es decir, una sociedad alternativa que dentro de un marco interpretativo colonial y bajo una estructura económica determinada apostó por una transformación económica y social, a partir de una estructura espacial que le permitía la interacción y confrontación con el blanco español. Como lo expresa Conde, los palenques fueron mucho más que simples espacios resistencia, también se establecieron como escenarios de reconfiguración social, económica y territorial de una comunidad expropiada:

(Los palenques) fueron vistos como simples espacios de resistencia en donde el esclavo fugitivo se refugiaba para escapar de las acciones punitivas de sus amos y las autoridades 
coloniales, perdiéndose el punto de vista de concebirlos como espacios sociales y económicos, y lugares donde los negros tejieron una densa red de símbolos, de imaginarios sociales y de vida cotidiana (Conde, 1999:22).

Una vez constituidos los palenques, se convertían en espacios para la reagrupación y consolidación de las familias. Según el historiador McFarlane (1991), quien iniciaba las huidas era el esposo, que regresaba después por su esposa e hijos; o a veces se conformaban grupos de parientes con la intención de huir hacia los palenques. Es decir, la figura del palenque estaba cargada de un fuerte simbolismo de resguardo y agrupación familiar para los esclavos que querían darse a la fuga; este territorio les daba la posibilidad de estar nuevamente con los familiares que habían sido esclavos por muchos años en las estancias de los blancos. Es decir, los palenques permitían un proceso de fortalecimiento de lazos familiares a través de la constitución de espacios de autonomía social.

Estos procesos de reagrupación familiar se desarrollaban en espacios de consolidación territorial bien establecidos. Pero en sus inicios, como se intentó demostrar en este artículo, las formas de cimarronaje y constitución de palenques fueron permeadas por cuestiones que iban más allá del sistema colonial: el lenguaje. Las fugas y los procesos de constitución de los palenques durante los siglos XVI y XVII en la antigua gobernación de Cartagena, dependían del tipo de caudillo al interior de los mismos, los cuales en su mayoría eran de origen africano; es decir, de múltiples lugares de este continente (Price, 1981).

Ante esta situación, era problemático el intento de fuga debido a las barreras lingüísticas que había entre los esclavos. Pero a pesar de ello, se fue desarrollando diversos mecanismos de comunicación ente si, los cuales les permitían tejer una red social lo suficientemente fuerte para poder establecer los criterios necesarios para realizar consensos, y a su vez, ejecutar acciones colectivas como medios de sublevación ante el sistema colonial esclavista.

Los palenques se fueron constituyendo como figuras de refugio y resistencia en la época neogranadina, frente a las diversas lógicas de explotación y de esclavitud que componían la estructura colonial española. El hecho de ser una figura de resistencia al sistema colonial, no significa que fueran totalmente aislados, ya que estos espacios se fueron convirtiendo en lugares de interacción social, no sólo entre los cimarrones que conformaban los palenques, sino con los centros poblacionales en los alrededores.

Hay que precisar la importancia de las lógicas territoriales que se establecieron alrededor de la figura de los palenques, ya que estos dependían y giraban en función de las lógicas territoriales que los rodeaban. Un área geográfica que paulatinamente fue apropiada y usada en torno a un proyecto de autonomía social por parte de los grupos cimarrones del Caribe Sabanero; este territorio fue "un espacio que permanecía por fuera del dominio de Cartagena y del Estado español, y ambos poderes eran incapaces para establecer un control 
real y efectivo sobre esos espacios y sus pobladores" (Conde, 1999: 27). Es decir, un lugar propicio para materializar expresiones de resistencia y autonomía territorial alternativas a las establecidas por el sistema esclavista durante las primeras tres centurias de la colonia.

\section{Referencias}

ARCILA, M. T. Y GÓMEZ, L. (2003). Una sociedad de frontera: El bajo Cauca-Nechí a fines del periodo colonial. En García, C. I. (Comp.), Fronteras Territorios y Metáforas. (pp. 273-287). Medellín, Colombia: Instituto de Estudios Regionales INER, Universidad de Antioquia, Hombre Nuevo Editores.

ARRÁZOLA, R. (1986). Palenque, primerpueblo libre de América. Bogotá, Colombia:Todo Impresores.

BLANCO, J. A. (1995). Censo de San Basilio de Palenque 1777. Análisis, comentarios y documentos. Memoria y Sociedad, 1 (1), 45-78.

BORREGO PLÁ, M. C. (1973). Palenques de negros en Cartagena de Indias a fines del siglo XVII. Sevilla, España: Escuela de Estudios Hispano-Americanos de Sevilla.

(1983). Cartagena de Indias en el siglo XVI. Sevilla, España: Escuela de Estudios HispanoAmericanos de Sevilla.

(1994). La conformación de una sociedad mestiza en la época de los Austrias 1540170o. En: Meisel Roca, A. (Ed.). Historia Económicay Social del Caribe Colombiano (pp. 59-108). Bogotá, Colombia: Ediciones Uninorte-ECOE Ediciones.

CONDE CALDERÓN, J. (1999). Espacio, Sociedady Conflicto en la provincia de Cartaegna 1740-1815. Barranquilla, Colombia: Colección de Ciencias Sociales y Económicas Rodrigo Noguera Barreche, Fondo de Publicaciones de la Universidad del Atlántico.

FALS BORDA, O. (1976). Capitalismo, Hacienda y Poblamiento en la Costa Atlántica. Bogotá, Colombia: Editorial Punta de Lanza.

(1979). Historia doble de la Costa. Tomo I. Mompóx y Loba. Bogotá, Colombia: Carlos Valencia Editores.

(1986). Historia doble de la Costa. Tomo IV. Retorno a la Tierra. Bogotá, Colombia: Carlos Valencia Editores.

LUCENA SALMORAL, M. (1962). Levantamiento de esclavos en Remedios. Boletín culturaly bibliográfico. 5 (9), 1127-1129.

(2005). Los códigos negros de la América Española. Alcalá, España: Ediciones UNESCOUniversidad de Alcalá.

MEISEL ROCA, A. (1980). Esclavitud, mestizaje y haciendas en la provincia de Cartagena: 1533- 
1851. Revista Desarrollo y Sociedad, 4, 227-278.

MUNIVE CONTRERAS, M. (2006). Resistencia estática: los negros colombianos contra la esclavitud: Cartagena y Mompox, siglo XVIII. Tiempos Modernos, Revista electrónica de Historia Moderna, 6 (14) Versión digital en: http://www.tiemposmodernos.org/tm3/index. $\mathrm{php} / \mathrm{tm} /$ article/viewFile/68/101

MCFARLANE, A. (1991). Cimarrones y palenques en Colombia: siglo XVIII. Revista Historia y Espacio, 14, 53-78.

NAVARRETE, M. C. (2001). Cimarrones y palenques en las provincias al norte del Nuevo Reino de Granada siglo XVII. Revista Fronteras de la Historia, 6, 97-126.

(2003). Los palenques. Reductos libertarios en la sociedad colonial, siglos XVI y XVII. Revista Historia y Sociedad, 7 (14), 77-96.

(2008). San Basilio de Palenque: Memoriay Tradición. Surgimiento y avatares de las gestas cimarronas en el Caribe colombiano. Cali, Colombia: Programa Editorial Universidad del Valle.

PRICE, R. (1981). Sociedades cimarronas: Comunidades esclavas rebeldes en las Américas. Colección América nuestra, América colonizada. México D.F., México: Siglo XXI.

RUIZ RIVERA, J. (2001). El cimarronaje en Cartagena de Indias: siglo XVII. Memoria, 8, 10-35.

TOVAR PINZÓN, H. (1994). Convocatoria al Poder del Número. Censos y Estadísticas de la Nueva Granada.1750-1830. Santafé de Bogotá, Colombia: Archivo General de la Nación.

YBOT LEÓN, A. (1952). La arteria histórica del Nuevo Reino de Granada. Bogotá, Colombia: Editorial ABC. 